\title{
COMPARISON OF TWO SAMPLING METHODS (CORER AND IN SITU SEDIMENT SIPPER METHODS) FOR THE PORE WATER OF SEDIMENT *)
}

by

\author{
Muswerry Muchtar
}

\begin{abstract}
Effect of two sampling techniques (i.e. corer and sipper samplers) of sediment pore water on measured concentrations of phosphate, nitrate and ammonia was examined. The concentrations of nitrate and ammonia in relation to sediment depth (vertical variations) collected by corer and sipper sampler do not show significant differences, while for phosphate concentrations significant differences occurred. The advantages and disadvantages of both techniques are discussed.
\end{abstract}

\section{INTRODUCTION}

Whether aquatic macrophytes take their nutrients from sediments or from open water has been discussed in the literature (Me Roy and Barsdate, 1970; Mc Roy and Goering, 1974; Iizumi et al., 1982; Thursby and Harlin, 1982)., showing conflicting statements. The general idea is that the pool with the highest concentration of nutrients (open water or pore water) is adding most to the nutrients budget. Nutrients are absorbed by seagrasses through both above and below-ground organs, i.e. sea grass may take up ammonium and to some extent nitrate from pore water through its roots and transport nitrogen to its leaves to meet metabolic requirements.

The study of estuarine pore water may help to assess a number of important environmental cases including:

1. The redox state (oxic - suboxic - anoxic) in estuarine sediments.

2. Storage of nutrient and potentially toxic chemical forms and their release to the overlying water.

3. Reactions which control mineral formation in sediments.

4. The chemical environment in contact with benthic ecosystems.

*)

Research and Development Center for Oceanology LIPI, Jakarta, Indonesia 
The determination of nutrients in pore water from marine sediments is difficult, because certain chemical and physical interactions affect the concentration and 'state' of the chemical form measured. For example, temperature (Bischoff and Ku, 1970; Fanning and Pilson, 1971) oxygen (Bray et al.,. 1973; Emerson 1976) and carbon dioxide (Emerson, 1976) affect the concentration of metrient in sediment pore waters collected, using sediment squeezers. One of the important needs in sampling sediment pore water is a device which can be used at a specific site, to take multiple samples over time and to be able to sample at discrete depths and diminish the effect of temperature and gas exchange on pore water nutrient concentration.

Several sampling methods have been used to obtain sediment samples and to collect water for chemical analyses. Several problems arise from each method. For example: by using corers. Fanning and Pilson (1971) have found that the warming of sea water-clay suspensions significantly alters the chemical composition of the interstitial waters. Two sampling methods: the ceramic and teflon in situ samplers have been compared by Zimmerman et al. (1978)

The purpose of the present study is to describe the results of corer and in situ sediment sipper samplers in sampling sediment pore waters, and to describe the possible advantages of the in situ sediment sipper.

\section{MATERIAL AND SAMPLING METHODS}

Samples were collected from the Zandkreek (May, 9, 23, 1989) and Grevelingen (June 7, 1989) lagoon (Figure 1), then kept in cool box to be transported lo the laboratory for analyses. The sediment cores from each station were collected by using teflon cylinders $30 \mathrm{~cm}$ in length and $6 \mathrm{~cm}$ in diameter (Figure 2A). The corers were pushed into the sediment stoppered at the top, carefully pulled out of the sediment.

The sediment column was divided into the following layers : surface to $1 \mathrm{~cm}, 1-3 \mathrm{~cm}, 3-5 \mathrm{~cm}$ and 5-10 $\mathrm{cm}$ and each layer is kept in plastic bags. The pore water samples were also collected using in situ sediment sipper (Figure 2B). The sampler was constructed of hollow PVC stake having a porous teflon collar. The stake was flushed with argon gas previous to sampling to make it free from liquid. It was then connected with a plastic syringe by a plastic tube. Then the syringe was sucked vacuum and the connection with the stake is stopped by using a clamp. In order to collect pore water from a number of depth intervals (e.g. 3 to $5 \mathrm{~cm}$ ) the sippers were inserted at the desired depths. When releasing the clamp, pore water from the depths corresponding with the porous collar of the sampler slowly seeped into the hollow stake. 


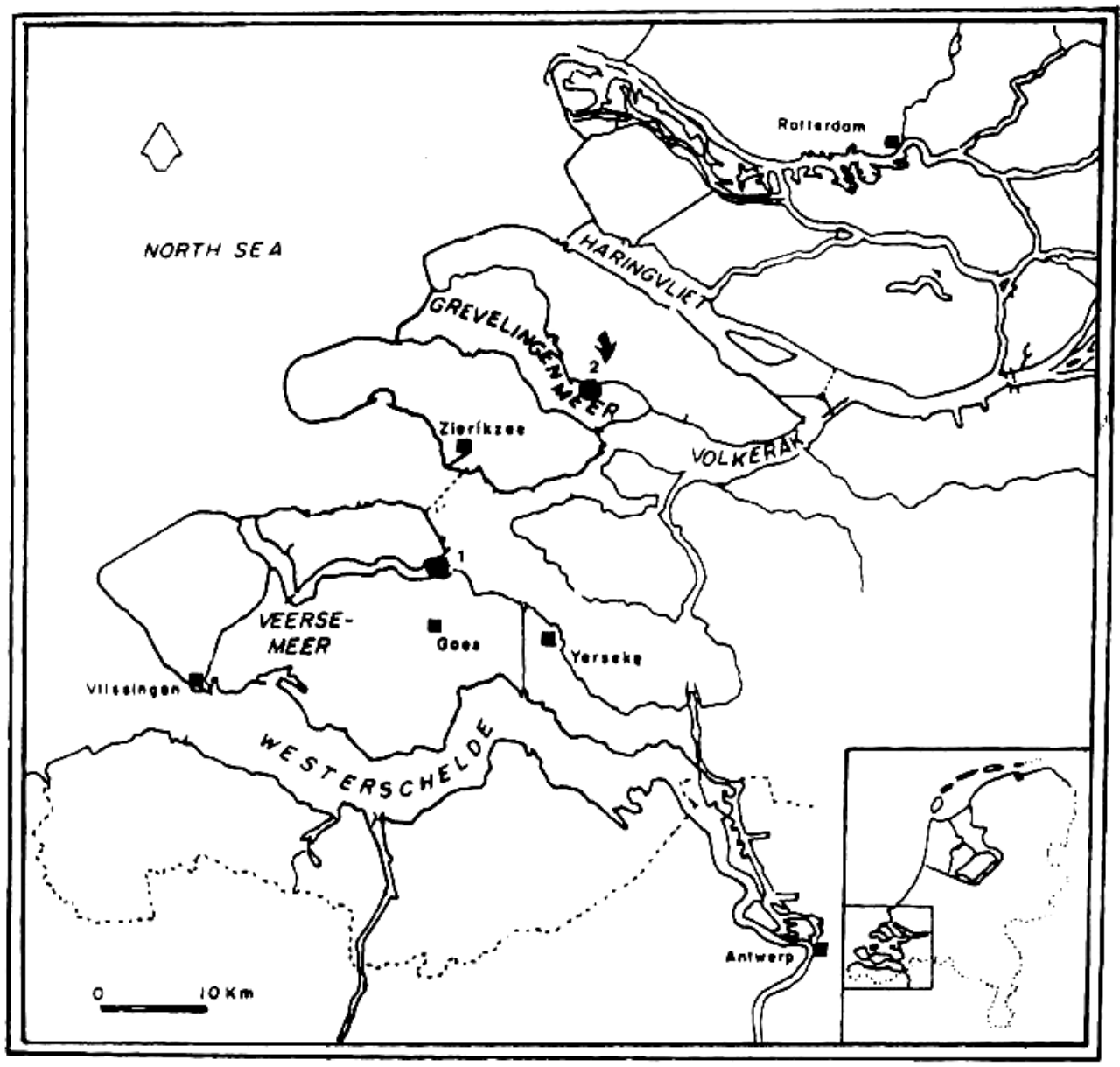

Figure 1. The S.W. Netherlands with the Zostera marina location studied (1 : Zankreek, 2 : Grevelingen). 


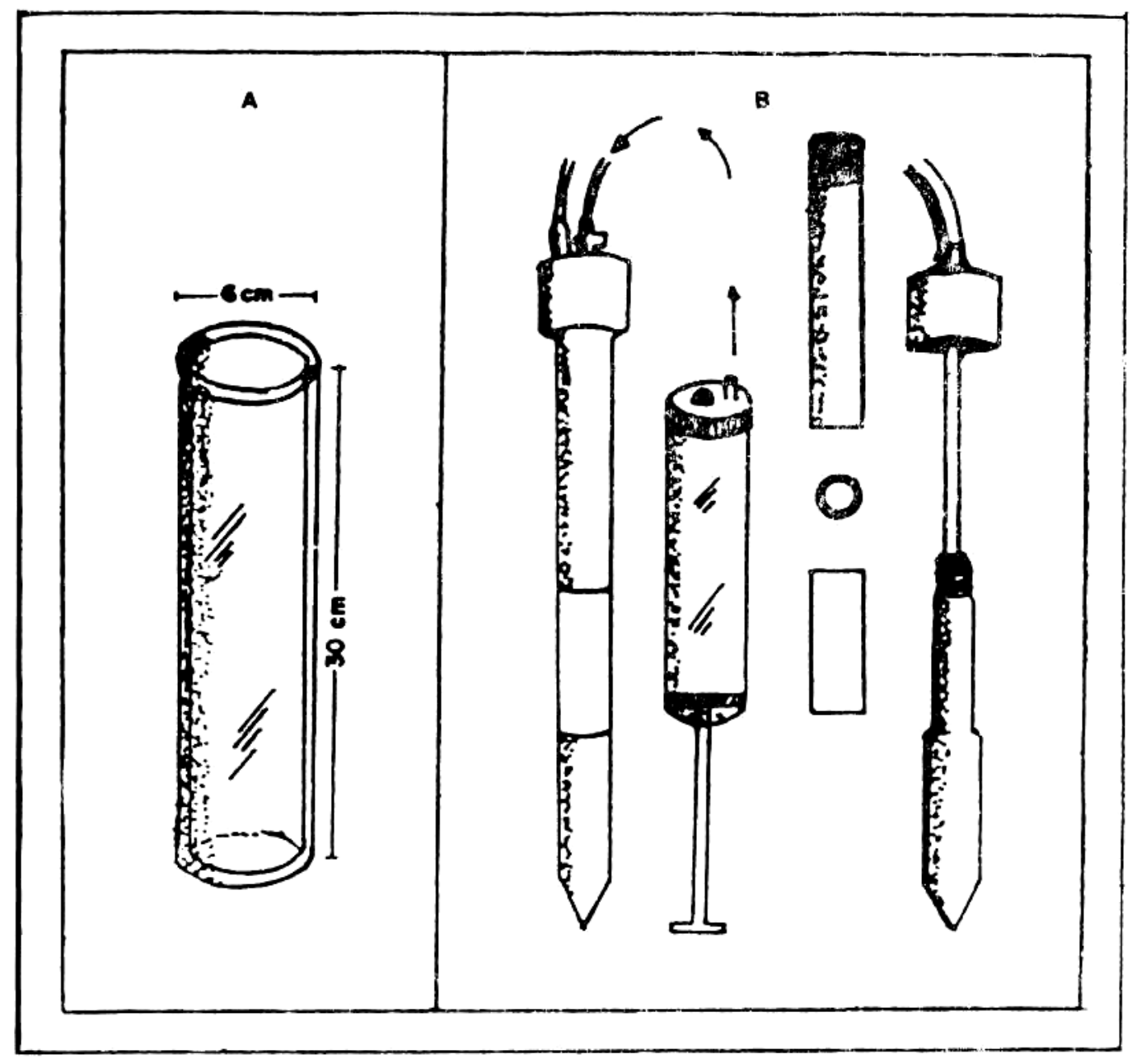

Figure 2 A : Correr sampler, B : Sediment Sipper Sampler 
$\cdot$

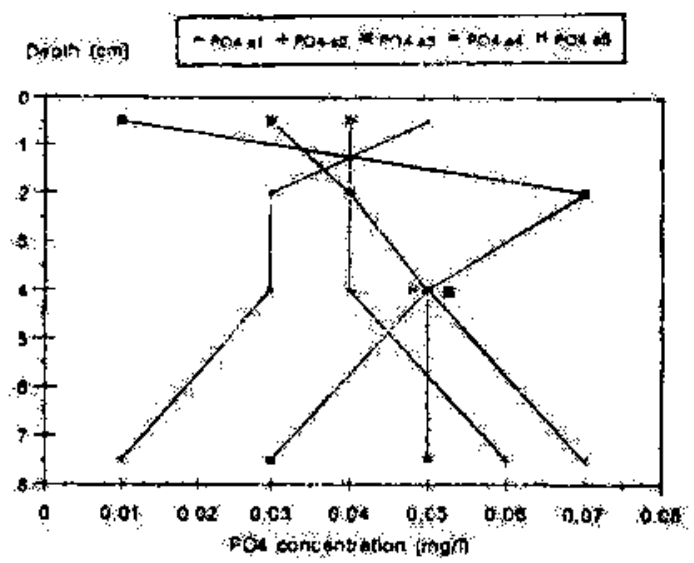

(c.

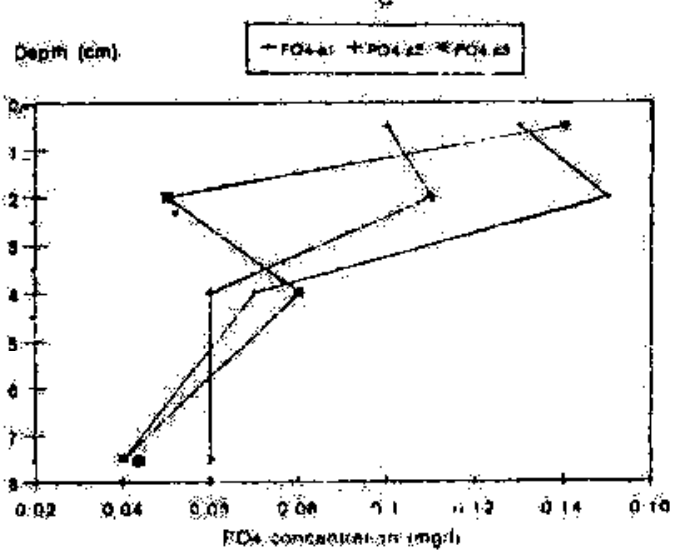

5

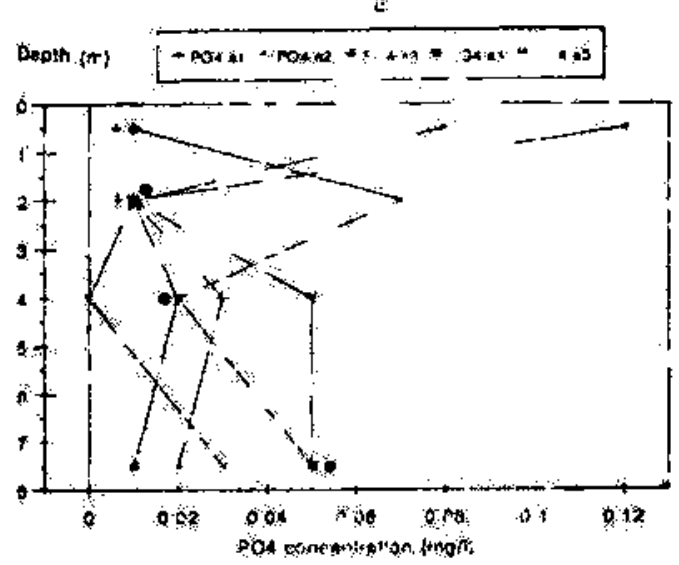

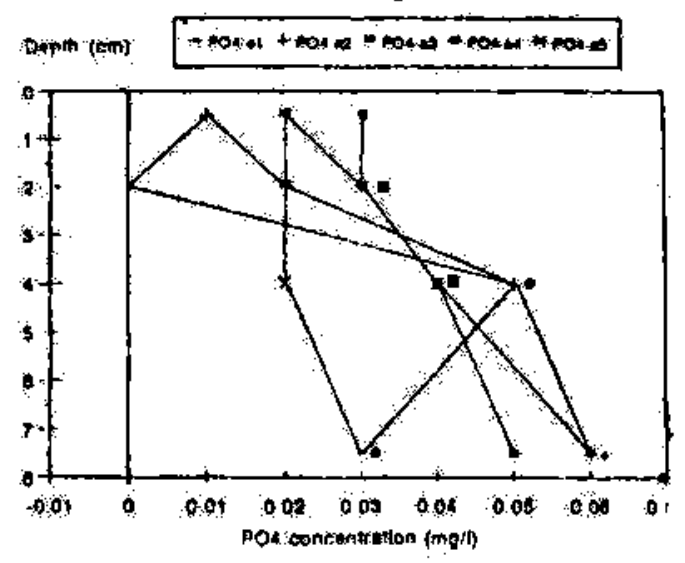

b

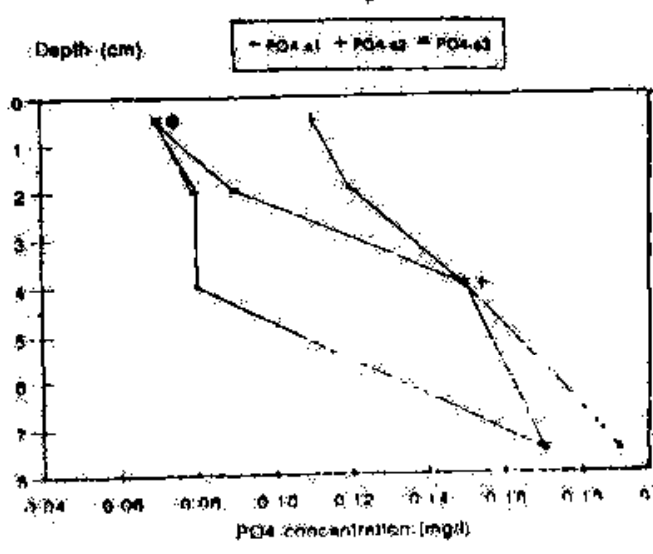

$\mathbf{F}$

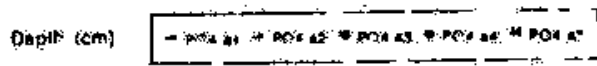

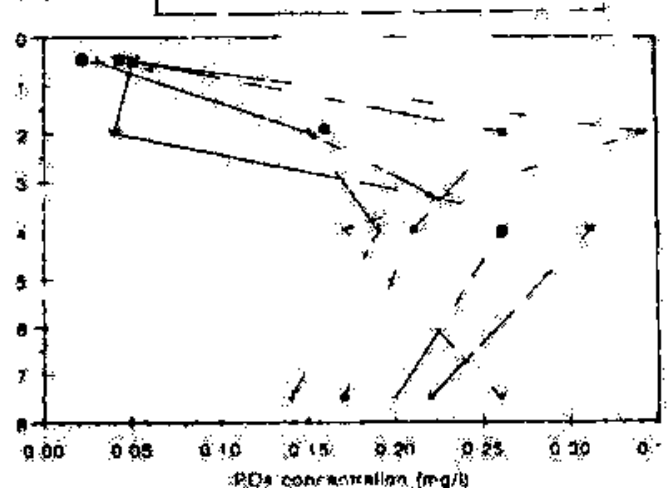

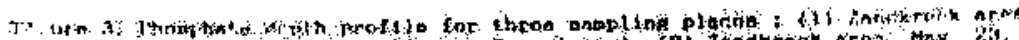

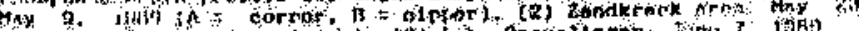

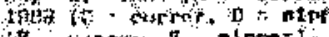

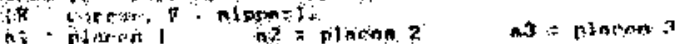

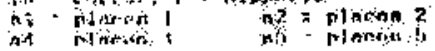


A

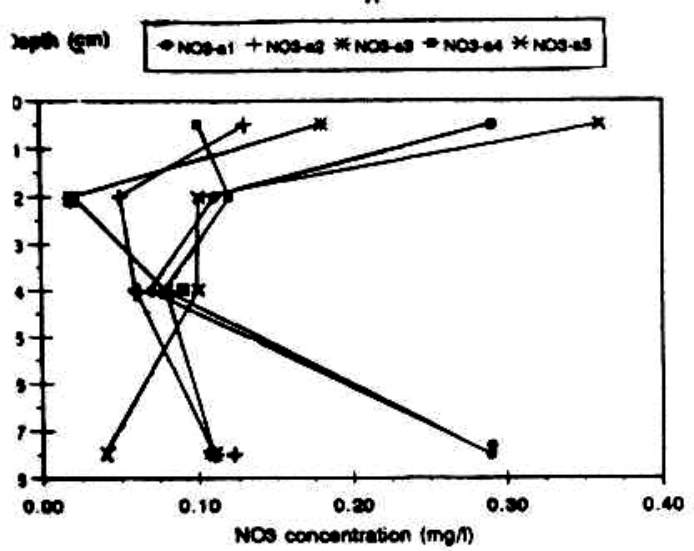

$c$
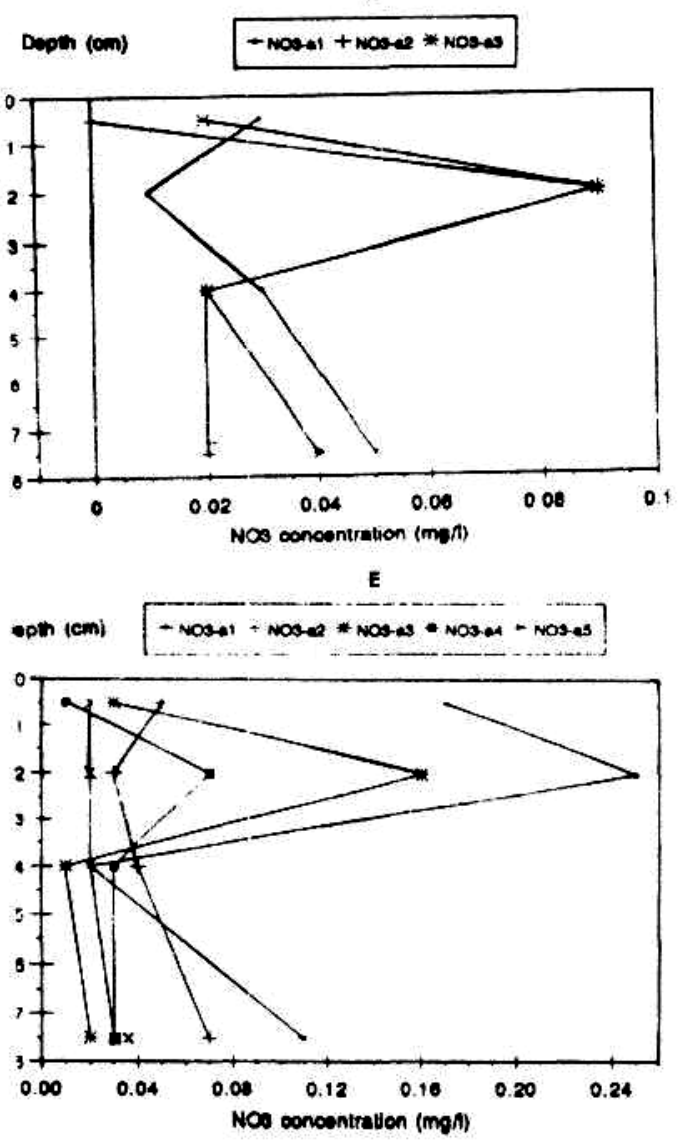
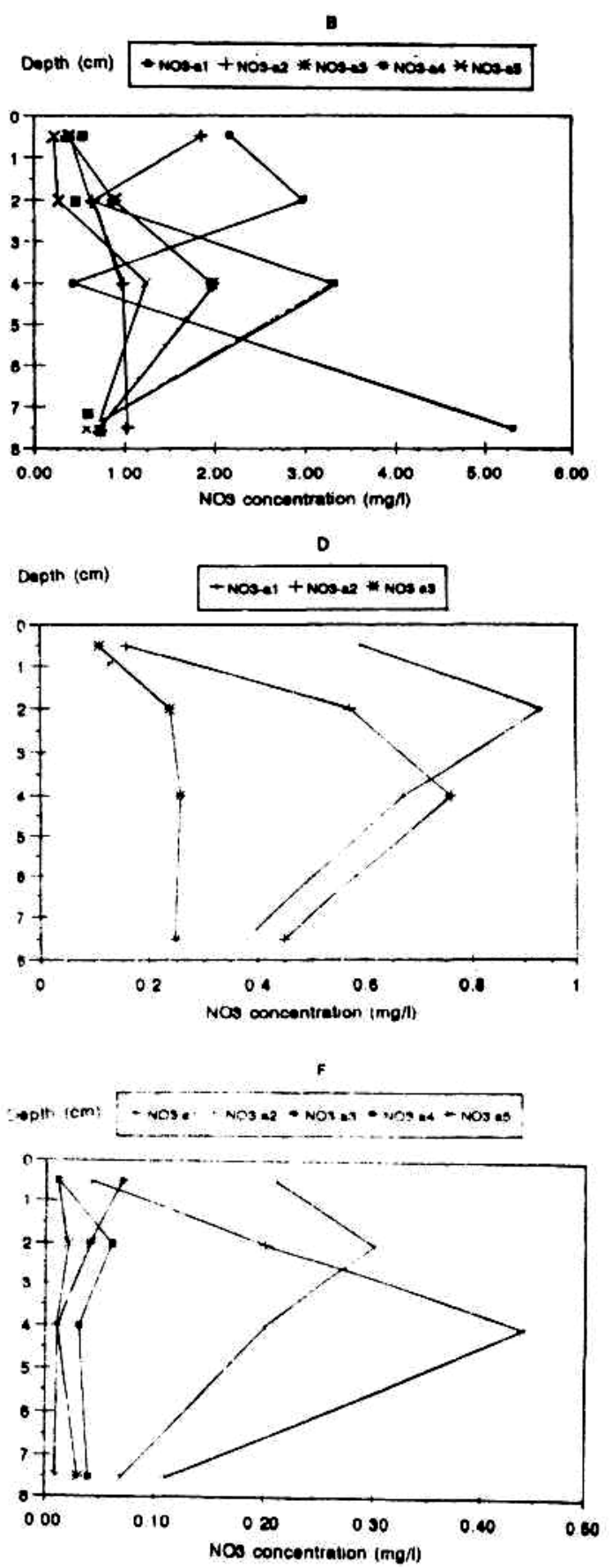

Fimure 4. Nitrate depth profile for three sampling places : (1) Zandkreek area, May B, 1989 ( $A=$ correr, B = aipper $)$. (2) Zandkreek area May 23, 1989 ( $C=$ correr. $D=$ alpper $)$. (3) Lake Grevellngen, June 7, 1989 ( $\mathrm{B}=$ correr, $\mathrm{Y}=$ alpper $)$.

a1 = places $1 \quad 22=$ places 2

n3 = places 3 

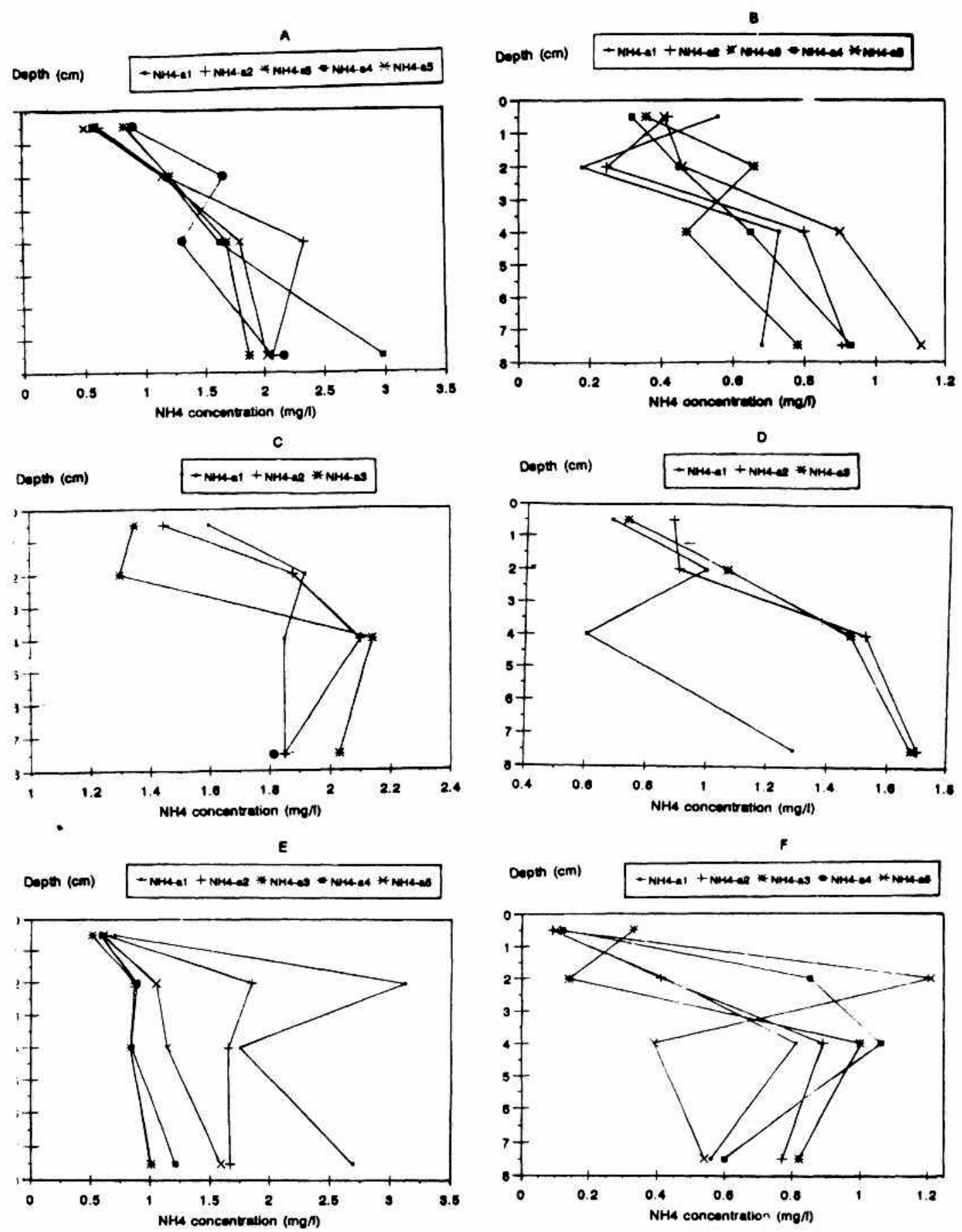

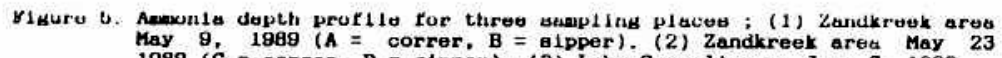
1989 ( $C=$ correr, $D=$ alpper). (3) Lake Grevelingen, June 7, 1989 ( $\mathrm{B}=$ correr. $\mathrm{F}=$ sipper)

$\begin{array}{lll}\text { a1 }=\text { places } 1 & \text { a2 }=\text { places } 2 & \text { a3 }=\text { places } 3 \\ \text { a4 }=\text { places } 4 & \text { a5 }=\text { places } 5 & \end{array}$ 


\section{LABORATORY PROCEDURE}

The pore water samples from the sediment taken by core sampler were removed through the plastic bottles with nitrogen gas at the pressure of 15 bar, and filtered by .using filter paper Whatman GF/C $0.45 \mu \mathrm{m}$ pore size, and removed to another plastic bottle with syringe containing filter paper Sartorius, $0.2 \mu \mathrm{m}$ pore size. The filtered samples for $\mathrm{PO}_{4}$ analyses were stored at about $5^{\circ} \mathrm{C}$, while the samples for $\mathrm{NO}_{3}$ and $\mathrm{NH}_{4}$ analyses were frozen.

Pore water samples collected using an in situ sediment sipper at depth: 0-1 cm, 3-5 cm and 5-10 cm were also removed to plastic bottles by using a syringe containing filter paper Sartorius, $0.2 \mu \mathrm{m}$ pore size. The same procedures as described above were followed: $\mathrm{PO}_{4}, \mathrm{NO}_{3}$ and $\mathrm{NH}_{4}$ concentrations were analyzed on a Technicon and a Skalar auto analyzer, based on a colorimetric method. The phosphate sample is allowed to react with a composite reagent containing molybdic acid, ascorbic acid and trivalent antimony.

The resulting complex is reduced to give a blue solution. The extinction of this solution is measured at 885 $\mathrm{nm}$ wave length. Nitrate is reduced almost quantitatively to nitrite when a sample is run through a column containing cadmium fillings, coated with metallic copper. The nitrate produced is then determined by diazotizing with sulfanilamide and coupling with $\mathrm{N}$ (I-naphtyl) - ethylenediamine to form a highly colored azo dye which can be measured spectrophotometrically at $543 \mathrm{~nm}$ wave length. The automated procedure for the determination of ammonium utilizes the Berthelot reaction, in which the formation of a blue colored compound, which is believed to be closely related to indephenol occurs when the solution of an ammonium salt is added to sodium phenoxide, followed by the addition of sodium hypochlorite. A solution of sodium citrate is added to the sample stream to eliminate the precipitation of the hydroxides of calcium and magnesium. Extinction values were read as $640 \mathrm{~nm}$ wave length. The data were analyzed statistically using Analysis of Variance.

\section{Results}

\section{RESULTS}

Concentrations of phosphate, nitrate and ammonium in Zandkreek and Grevelingen pore water are shown in Figures 3, 4 and 5. Taking all the data together and without distinguishing between the separate sediment layers there were significant differences between the two sampling methods (phosphate with F-ratio $=25$. 42; $\mathrm{P}<0.05$, nitrate with F-ratio $=21.51 ; \mathrm{P}<0.05$ and ammonium with $\mathrm{F}$-ratio $=110.294 ; \mathrm{P}<0.05$. When comparing the effect of both sampling methods on the concentration of nitrate and ammonium in relation to sediment depths (vertical variations), there were no 
significant differences nitrate with (F-ratio $=0.406 ; \mathrm{P}>0.05)$ ammonium with $(\mathrm{F}$-ratio $=2.366 \mathrm{P}>0.05)$, while for phosphate concentration significant differences occurred (F-ratio $=5.645 ; \mathrm{P}<0.05$ ). As shown in Figure 3, generally the maximum concentration of phosphate by using the core sampler, occurred at the surface of the sediments $(0$ to $1 \mathrm{~cm})$ showing a negative tendency into deeper sediment layers where the phosphate concentration decreased from 5 to $10 \mathrm{~cm}$ depth. While using in situ sediment sipper sampler, generally, the maximum concentration occurred at 5 to $10 \mathrm{~cm}$ depth (positive tendency).

Nitrate concentrations obtained by using corer and sipper methods showed that the maximum nitrate concentration occurred at 1 to $3 \mathrm{~cm}$ depth (Figure 4). The ammonium concentration increased from the sediment surface down to 5-10 cm, using both methods (Figure 5).

\section{DISCUSSION}

Comparison of the results obtained by corer and in situ sediment sipper sampler, indicated that the in situ sediment sipper sampler has many advantages. First of all, it is easy to operate in the field. The sampler can be precisely located at a desired depth, then left in one place without disturbing the sediment while sampling. The samples taken with this kind of sampler were less contaminated with air (atmosphere) than those taken with a corer. This system is presently used to measure trace metals, salinity, organic carbon as well as nutrient. Other advantage is that sipper sampler did not appear to influence the concentrations measured in pore water as long as proper precautions were taken to prevent the loss of reduced compounds.

When using a core sampler, the collextion of core disturbs the sediment and only one sample can be taken from a specific spot, while the sipper sampler can take more than o le sample, Also, with a core sampler, the material squeezed is characteristically messy and the quantity of pore water collected is minimum.

In vertical distribution, corer results showed that the phosphate concentrations were higher at the surface and decreased towards 5-10 cm depth. This distribution may, however, be due to the core sampler, destroying the new grown roots of seagrass (root damage by cutting). This is in agreement with the findings of Brian (1985). He found that the corer sectioning technique significantly increased the concentration of nutrients, due to root damage by cutting.

The vertical profiles of the concentration obtained with the in situ sediment sipper sampler, phosphate and ammonium increased to a maximum at 5 to $10 \mathrm{~cm}$. This type of profile was also found by McRoy et al. (1972) and Montgomery et al. (1978) beneath Zostera beds. The nitrate profile determined in this work is also in agreement with the investigations as shown by the results of Vanderbogth and Billen (1975) and Montgomery et al. (1978) who found maximum concentrations of nitrate at approximately $2 \mathrm{~cm}$ (which is $1 \mathrm{~cm}$ to $3 \mathrm{~cm}$ depth in the present study).

The core sampler results also showed that the ammonium concentration increased to a maximum at 5 to 10 $\mathrm{cm}$ depth and maximum nitrate concentration was also found at 1 to $5 \mathrm{~cm}$. But phosphate concentration generally showed a decrease to 5-10 cm depth. This may be due to the fact that the coring technique disturbed or damaged the root system of the seagrass in the seagrass bed.

\section{CONCLUSION}

Comparing the two sampling methods (corer and in situ sediment sipper method) for the determination of phosphate, nitrate and ammonium in pore water of sediments concludes:

- All phosphate, nitrate and ammonium concentrations which were analyzed from corer and in situ sediment sipper show different results.

- The in situ sediment sipper sampler has many advantages :

- easy to handle and easy to operate in the field,

- the sampler can be precisely located at a desired depth,

- with this kind of sampler, several samples may be collected from the same site and depth without 
disturbing the sediment,

- the sample is less contaminated by contact with the air (atmosphere). Concentration measured in pore water did not appear to be influenced as long as proper precautions were taken to prevent the loss of reduced compound,

- the sampler can be used to analyze another chemical parameter i.e. trace/heavy metals and salinity.

- In vertical profiles (interaction between methods and variation in depths), significant differences occurred in phosphate concentration. This is due to the fact that the core sampler destroyed the roots of seagrass which had just grown in the surface layer (negative tendency in corer method, positive tendency in sipper method.). 


\section{REFERENCES}

Bischoff, Jl. and T.L. Ku., 1970. Pore fluids of recent marine sediments-I. oxidizing sediments of $20^{\circ} \mathrm{N}$, Continental Rise to Mid-Atlantic Ridge. J. Sediment Petrol 40.960.

Bray, J.T., O.P. Brikes and B.N., Troup, 1973. Phosphate interstitial waters of anoxic sediments: oxidation effects during sampling procedures. Science, N.Y. 180: 1362-1364.

Brian, L.H., 1985. Effects of sampling techniques on measurements of pore water constituents in salt march sediments. Limnol. Oceanogr. 30 (]) 221 -227.

Emerson, S., 1976. Early diagenesis in anaerobic lake sediment: chemical equilibria in interstitial waters. Geochimica et Cosmochimica Acta 40. 925-934.

Fanning, K.A. and M.E. Pilson., 1971. Interstitial silica and $\mathrm{pH}$ in marine sediment: some effects of sampling procedures. Science N.Y. 173: 1228-1231.

Iizumi, H.; A. Hattori and C.P. McRoy., 1982. Ammonium regeneration and assimilation in eelgrass (Zostera marina) beds. Mar. Biol. 66: 59-65.

McRoy, C.P. and R.J. Barsdate, 1970. Phosphate absorption in eelgrass. Limnol. Oceanogr. 15: 6-13.

McRoy, C.P.; R.J. Barsdate and M. Nebert., 1972. Phosphorus cycling in an eelgrass (Zostera marina L.) ecosystem. Limnol. Oceanogr. 17: 58-67.

McRoy, C.P. and J.J. Goering., 1974. Nutrient transfer between the seagrass Zostera marina and its ephiphytes. Nature Cond., Vol. 248: pp 173-174.

Montgomery, J.R.; Carl. F. Zimmerman and Mary T. Price., 1978. The collection, analysis and variation of nutrients in estuarine pore water. Estuar. Cstl. Mar. Sci. 9: 203-214.

Thursby, G.B. and M.M. Harlin., 1982. Leaf root in the uptake of ammonium by Zostera marina. Mar. Biol., 72: $109-112$.

Vanderborgth, J.P. and G. Billen., 1975. Vertical distribution of nitrate concentration in pore water of marine sediments with nitrification and denitrification. Limnol. Oceanogr. 20: 953-961.

Zimmerman, C.; M. Price and J. Montgomery., 1978. A comparison of ceramic and teflon in situ samplers for nutrient pore water determinations. Estuarine and Coast. Mar. Science 7 : 93-97. 